\title{
O DESIGN APLICADO AOS AMBIENTES: REFLEXÕES E OBSERVAÇÕES SOBRE A NOSSA HISTÓRIA
}

Paulo Roberto Gonçalves de Oliveira

Universidade do Oeste Paulista - Unoeste

paulooliveira@unoeste.br

Resumo: É comum ouvirmos e lermos que o Design de Interiores é uma profissão recente ou nova, que nasceu apenas no século XX e também, que a sua atuação está restrita ao objeto arquitetônico. Faz-se necessário que a academia e os profissionais da área passem a refutá-las, para o bem e a integridade da profissão. Certeau nos mostra que a História como a conhecemos nem sempre condiz com a realidade afinal, ela representa a visão do "mais forte". Pesquisas acadêmicas sobre a História do Design de Interiores devem ser estimuladas investigando, nos lastros da existência humana, a presença do designer. Tais dados podem ser encontrados na pluralidade dos livros de História, em documentos da Arqueologia e da Antropologia, nos panfletos e tablóides da antiguidade e diversos outros materiais. Neste artigo são apresentados apontamentos sobre a existência histórica do "pensamento do Design de Interiores" abrindo, portanto, uma janela para pesquisas futuras sobre este assunto, necessário à construção do estatuto epistemológico da profissão.

Palavras-chave: Design, Design de Interiores, História.

Resumo: We often hear and read that interior design is a recent or new profession that originated only in the twentieth century and also that its activities are restricted to architecture. It is imperative that academia and professionals start to refute such claims, for the good and the integrity of the profession. Certeau shows us that history as we know it is not always consistent with reality; after all, it is the version of the dominant classes. Academic research on the history of interior design should be encouraged to investigate the presence of the designer in human history. Such data can be found in the abundance of history books, documents of Archaeology and Anthropology, pamphlets and tabloids of antiquity and many other materials. This article presents the historical existence of the "thought of Interior Design", thus opening a window for future research on this subject, necessary for the construction of the epistemological status of the profession.

Keywords: Design, Interior Design, History. 


\section{INTRODUÇÃO}

A organização de cada historiografia em função de óticas particulares e diversas se refere a atos históricos, fundadores de sentidos e instauradores de ciências. (CERTEAU, 1982, pp 35).

Os estudos sobre a Filosofia da História e também sobre a Escrita da História nos mostram que este é um conhecimento que vem sendo, desde sempre, sistematicamente escrito e reescrito de acordo com os interesses de grupos. Fato é que hoje temos incontáveis versões da Bíblia, cada uma atendendo os interesses doutrinários de sua denominação onde vemos textos alterados, palavras inexistentes no período bíblico e que vem sendo inseridas e aplicadas em - e com - contextos distorcidos relativizando, assim, a história religiosa. É um claro desrespeito à Bíblia original.

Para basear a linha de raciocínio deste artigo, foi utilizado o livro de MICHEL DE CERTEAU, A Escrita da História. Certeau faz uma profunda análise histórica sobre como a ideologia religiosa se impôs e moldou a História ao mesmo tempo em que lutava contra as suas próprias contradições e inconsistências. É importante perceber como a difusão da História manipulada por um determinado grupo (ou uma determinada área profissional) pode levar a uma degradação progressiva da sua própria História, bem como, a falta de pesquisas e análises contraditórias pode reforçar a ideia imposta de uma "história inexistente" sobre outros grupos, como é o nosso caso.

Esta pesquisa busca em livros, em periódicos e outros documentos coletados pela internet estes lastros perdidos e/ou esquecidos, trazendo à tona fatos que comprovam a existência da forma de pensar do designer muito antes das datas apontadas oficialmente como o início da profissão.

\section{DESENVOLVIMENTO}

\subsection{Fundamentação teórica}

É comum vermos a História do Design de Interiores amarrada à História da Arquitetura. Não questiono isso já que, de maneira bem específica e pontual, estas áreas sempre estiveram muito próximas e atuando juntas afinal, são complementares. Porém, apenas em sua relação no tocante ao elemento arquitetônico quando o projeto envolve o mesmo. Com isso, não podemos permitir que estas amarras cerceiem ou sirvam de justificativas para o impedimento do pleno exercício profissional do designer.

Também não podemos pensar na História do Design de Interiores apenas por dados relativos ao nosso país. Ressalto que ela é uma profissão internacionalizada assim como todas as outras e que faz parte do cotidiano de qualquer pessoa direta ou indiretamente. Da mesma forma, não devemos acatar passivamente a História oficial que conhecemos, moldada e escrita por, em sua maioria, não-designers. Ao aceitarmos este tipo de abordagem histórica eliminamos todos os lastros do "pensar o 
melhor uso dos espaços ${ }^{1 "}$ - um dos pilares de nossa profissão - claramente percebidos na História da humanidade em diversos materiais disponíveis em bibliotecas, livros, tablóides e periódicos. Nesse sentido fica claro que diversas pistas acabaram sendo descartadas, pois a "versão oficial" que nos fazem acreditar como verdadeira, desconsidera e/ou distorce elementos importantes para que a mesma passe a atender aos interesses destes grupos dominantes.

Percebe-se que a História é marcada por um constante conflito entre a historiografia e a arqueologia. Com isso, não devemos acatar estas imposições ideológicas - aqui, corporativistas - sempre alterando, omitindo, distorcendo aspectos, elementos e fatos importantes em benefício de apenas um determinado grupo sem os devidos questionamentos. Tais detalhes, por vezes sutis, podem conter lastros importantes para a nossa História real. ${ }^{2}$

Certamente, em seu uso corrente, o termo história conota, sucessivamente, a ciência e seu objeto - a explicação que se diz e a realidade daquilo que se passou ou se passa. [...] O próprio termo "história" já sugere uma particular proximidade entre a operação científica e a realidade que ela analisa. (CERTEAU, 1982, pp 24).

Ao nos apresentar esta descrição, Certeau nos dá maior clareza de que os fatos retratados nas justificativas históricas são carregadas de imprecisões - propositais - da realidade do passado. Não à toa percebemos um insistente avanço da área de Arquitetura sobre a Arqueologia, impondo às descobertas que "tudo contido no sítio é Arquitetura". O mesmo fez a Igreja quando impôs a historiografia sobre a arqueologia para, através dos midraxes que são a base de sua ideologia/doutrina, como bem nos mostra Certeau quando, referindo-se ao trabalho do historiador, afirma que "como objeto de seu trabalho, a teologia se lhe apresenta sob duas formalidades igualmente incertas na historiografia; é um fato religioso; é um fato de doutrina." ${ }^{3}$

Somos condicionados a pensar através de uma História "oficial" que nos é repassada pela academia. É comum aceitarmos passivamente a ideia de que a primeira habitação humana é fruto da Arquitetura. Se há refutações sobre isto, não receberam o devido reconhecimento e respeito. Devemos reconhecer o homem desde os primórdios, como elemento básico de transformação. A caverna é um refúgio, um abrigo, seu primeiro espaço de moradia, quando ele tem o elemento disponível à sua volta, ou seja, elevados rochosos, cavernas subterrâneas ou similares. Um ser, minimamente crítico, percebe o quão óbvio uma caverna representa apenas um espaço elaborado pela própria natureza e não pelo homem - não há projeto da caverna. Vemos neste simples exemplo, o apoderamento de algo que não pertence àqueles que dele se vangloriam como se feitos históricos de sua área o fosse. Certeau, em uma nota de rodapé (3) explicando o termo "produção" nos aponta que

Aqui como em muitos outros casos (cf. por "manifestação", "aparição" e até por "ação"), uma pressão da linguagem corrente leva o sentido a se transformar do ato em seu resultado, do ativo do fazer ao passivo do ser visto, do gesto à sua imagem no espelho. Uma

\footnotetext{
${ }^{1}$ Refere-se aqui a todo o processo envolvido no desenvolvimento e implantação de um projeto de Design, respeitando sua metodologia e suas etapas.

${ }^{2}$ CERTEAU, Escrita da história, 1982.

${ }^{3}$ Idem, pp 26.
} 
clivagem crescente entre a pesquisa e a vulgarização ocorre tanto na história quanto na teologia: as pesquisas tomam a forma de meios específicos e diferenciados por procedimentos próprios; mas, na sua "vulgarização", a história e a teologia se tornam objetos de saber ou de curiosidade, distribuídos e impostos a um "público" de consumidores que participa cada vez menos da produção. (CERTEAU, 1982, pp 24).

O que aconteceria se os designers passassem a estudar e analisar o trabalho arqueológico buscando as pistas do início de sua profissão? Certamente teríamos uma reviravolta na História do Design, já que muitas das teorias que conhecemos hoje e tidas como fatos incontestáveis podem ruir dando lugar a novos olhares multidisciplinares. Nesse sentido, o Design precisa desligar-se do ranço "industrial" produção seriada - e assumir que os antigos mestres artesãos também projetavam antes de executar seus objetos. São, pois, os "pais e mães" da profissão. Caso não se admita isso, o que são e o que fazem os designers que trabalham com o padrão AA, produzindo poucas peças que não atingem o padrão seriado de quantidade industrial? Eles não são, então, designers? Certeau nos aponta sobre isso:

E se o sentido não pode ser apreendido sob a forma de um conhecimento particular que seria extraído do real ou que lhe seria acrescentado, é porque todo "fato histórico" resulta de uma práxis, porque ela já é o signo de um ato e, portanto, a afirmação de um sentido. Este resulta dos procedimentos que permitiram articular um modo de compreensão num discurso de "fatos". (CERTEAU, 1982, pp 35).

É fato que há um movimento impondo a ideia de que o Design de Interiores surgiu como área recentemente e é ligado apenas ao objeto arquitetônico. Podemos até levar esse argumento como verdadeiro se analisarmos sob a ótica educacional afinal, aqui no Brasil, os primeiros cursos oficiais surgiram apenas na metade do século passado com claros reflexos do pensamento da Bauhaus. Mas, estudando a escola, vemos que Gropius ${ }^{4}$ propôs uma reformulação pedagógica que levou ao fim dos diversos ateliês independentes de prática das Artes. Estes foram transformados em meras disciplinas e considerados elementos inseparáveis da Arquitetura. Nas palavras de Gropius, eram práticas que "dependiam da Arquitetura para existir". Vale ressaltar também, como destaca Wolfe ${ }^{5}$ (1990), que no inicio da Bauhaus, a vinda destes mestres-artesãos para a escola já havia sido planejada para que estes produzissem mais voltados para os interiores arquitetônicos que para a sua verdadeira função enquanto produtores independentes. Foi uma tentativa de "reinventar" a Arquitetura, transformando-a em algo totalitário e acima de todas as outras áreas. Não havia intenção de promover e integrar (interação/cooperação) entre as Artes e Ofícios com a Arquitetura e sim, demonstra uma afronta ao livre exercício profissional de outras áreas criativas.

O estilo Bauhaus na verdade era uma apropriação de movimentos artísticos que estavam ocorrendo no período com um viés do

\footnotetext{
4 "Bauhaus: Novarquitetura", 1974 - 2 ed.

${ }^{5}$ Da Bauhaus ao nosso caos. Ed. Rocco, 1990.
} 
socialismo impregnado na época pelo cenário de destruição e esperança do pós-guerra. ${ }^{6}$ (NETO, 2011, pp 103).

Assim conseguimos entender como a ligação de nossa área com a Arquitetura é algo ilusório. Esta "amarra" (no ideário acadêmico e de mercado) não passa de uma visão ufanista impregnada de considerações distorcidas, reflexos do período Bauhausiano?.

Adrian Forty ${ }^{8}$ (2013), especialmente no capitulo denominado "O Lar", retrata como eram pensados os espaços residenciais antes da Bauhaus. No período concomitante à Revolução Industrial ${ }^{9}$, e após este chegando aos dias de hoje, que surgiu este pensar, esta distorção, que habita o imaginário sobre o conceito da área de Design de Interiores. Quando houve a Revolução Industrial, criou-se uma ideia de que o Design era algo que devia ser industrializado ${ }^{10}$ e somente então a profissão de desenhista industrial foi considerada ou validada. Mas percebe-se que há aqui a mesma despreocupação com lastros históricos desta prática, incluindo dados descritos de forma distorcida em livros.

\subsection{Reescrevendo a nossa história - reflexões e observações sobre a nossa linha do tempo.}

Desde o século XVIII o labor de desenvolver os ambientes era realizado por tapeceiros e estofadores. Estes artesãos definiam os materiais, os revestimentos e as formas. Porém houve uma forte reação à incapacidade destes de fornecer móveis e projetos de decoração que atendessem aos novos conceitos e padrões morais.

$\mathrm{Na}$ época Vitoriana ${ }^{11}$, estes padrões morais foçaram a separação entre o espaço de trabalho do espaço denominado "lar". O primeiro destinado ao ofício e o segundo ficara reservado para o convívio familiar e social. Esta tendência levou a casa a contemplar aspectos diferenciados representados pela Decoração e pelo Design dos objetos inseridos nos diversos espaços da realidade urbana (externa) desvinculando, assim, a habitação do espaço de trabalho.

Isso nos mostra a visão, vigente até os dias atuais, de que o lar busca contrapor os espaços frios dos ambientes de trabalho ${ }^{12}$. Passaram a ser um espaço onde as energias dispensadas no labor diário poderiam ser recuperadas através da "paz" e do isolamento que este espaço passou a refletir: antes um ambiente múltiplo onde o trabalho, muitas vezes artesanal, e a convivência familiar dividiam os mesmos espaços, agora um ambiente íntimo destinado apenas à família e aos poucos convidados.

Desse modo, o lar passou a ser considerado um repositório das virtudes perdidas ou negadas no mundo exterior. Para as classes

\footnotetext{
${ }^{6}$ Bauhaus e o Jardim de Epicuro: Discurso e Prática. Estação das Letras e Cores, 2011

7 Pensamento ainda empregado nos dias atuais. Academia, órgãos e profissionais da Arquitetura repetem estes discursos que representam o absolutismo arquitetônico sendo imposto.

${ }^{8}$ Objetos de Desejo. Ed. Cosac Naify, 2013.

${ }^{9}$ A Primeira etapa da Revolução Industrial ocorreu entre 1760 a 1860. A Segunda Etapa ocorreu no período de 1860 a 1900. A Terceira Etapa considera os avanços tecnológicos do século XX e XXI.

${ }^{10}$ Produzido em larga escala, mecanicamente ou manufaturadas.

11 Junho de 1837 a janeiro de 1901.

12 Hoje temos a ideia dos home offices. Um movimento contrário à ideia de separação dos ambientes.
} 
medias do século XIX, lar significava sentimento, sinceridade, honestidade, verdade e amor. Essa representação do lar compreendia uma dissociação completa de todas as coisas boas do mundo público e de todas as coisas ruins do mundo doméstico. Era transformar o lar em um lugar de ficção, um lugar onde florescia a ilusão. Essas condições de exclusão artificial de todos os sentimentos "ruins" do lar, combinadas a um ócio intelectual forçado, proporcionaram, como Sigmund Freud e Joseph Breuer observariam na década de 1890, o clima para a histeria, um dos males mais comuns das mulheres burguesas do século XIX. (FORTY, 2013, pp. 140).

Forty destaca também que a partir de 1860 começaram a surgir manuais - ou tablóides - que ditavam padrões de bom gosto e serviam para reforçar as funções sociais das mulheres e como isso as levou a manterem-se afastadas do mundo do trabalho (ao menos as burguesas ${ }^{13}$ ). Além dos afazeres domésticos e das prendas ${ }^{14}$ que deviam possuir como sinônimo de valorização pessoal, ficam responsáveis também pelo cuidado e pela Decoração de seus lares. O marido trazia o sustento e a esposa zelava, mantinha e renova a casa. Este ato de cuidar do lar aumentava o rol de prendas esperadas de uma mulher: definir os mobiliários, cores, texturas e objetos que comporiam os ambientes e elas, agora, até mesmo pintavam e empapelavam as paredes ${ }^{15}$.

Tais manuais, em sua maioria, eram escritos por mulheres ${ }^{16}$ que trabalhavam especificamente com esta área. No período de 1800, Rhoda e Agnes Garret eram decoradoras e diretoras de uma escola de Decoração. De 1880 a 1890 a Sra Panton escrevia uma coluna semanal no The Lady Pictorial ${ }^{17}$, falando sobre o tema e também prestava consultorias. Elsie de Wolf e Edith Wharton já contavam com respeito em NY como designers de interiores com vasto portfólio.

Com estas atitudes, diversas metáforas e imagens alegóricas sobre o "lar perfeito" foram sendo criadas. Em 1913 Elsie de Wolf escreveu ${ }^{18}$ que

[...] um homem pode construir e decorar uma linda casa, mas cabe à mulher fazer dela um lar para ele. É a personalidade da dona da casa expressa. Os homens são para sempre convidados em nossos lares, não importa quanta felicidade eles possam encontrar ali. (WOLF, 1913, pp.5)

O que não contavam é que este aprisionamento das mulheres as levariam ao ócio forçado e à histeria. Percebe-se a busca pela personalidade no lar, porém

\footnotetext{
${ }^{13}$ Aqui podemos perceber claramente a origem da concepção de que nossa área está relacionada aos projetos dignos de capas de revistas, bem como esta ser uma atividade feminina.

${ }^{14}$ Prendado - adj. Dotado de muitas e boas qualidades. / Que tem esmerada educação.

prenda - s.f. Presente, dádiva. / Qualidade, dom. / Aptidão; conhecimentos; arte; habilidade. / Bras. (RS) Jóia. // Fam. e Ironic. É uma...

${ }^{15} \mathrm{Não}$ à toa que ainda hoje vemos nossas clientes (esposas) dominando o pensar sobre como deve ser o projeto, definindo questões pertinentes a outros usuários (esposo, filhos, etc.).

${ }^{16}$ Ms. Haweis, Ms. Paton, Ms. Edith Wharton, Ms. Ogden Codman, Ms. Elsie de Wolf entre outras.

${ }^{17}$ Lady's Pictorial - In print: 1891. The Lady's Pictorial was a periodical aimed squarely at middle class women, and a rival to The Queen. It regularly printed articles on the enlargement of women's sphere, particularly in employment. A large number of women were employed on the staff.

${ }^{18}$ The house in good taste. The Century Co, 1913.
} 
representando apenas a da senhora. Este conceito de que os interiores devem mostrar o caráter pessoal foi amplificado no século XIX quando as aparências (status) contavam mais que o verdadeiro caráter. Este pensamento era tão sério que, a mulher que não fosse capaz de expressar a sua personalidade através da Decoração era tida como menos feminina. Percebe-se então, que a profissão de Decoração já existe, ao menos, desde o final dos anos 1700 de maneira formal (estas senhoras citadas) bem como informal (as donas de casa) ${ }^{19}$.

Como se vê, tudo isso tem a ver com convenções sociais de períodos específicos. Tais convenções são criadas por grupos dominantes e que as impõem como verdades absolutas dentro do contexto do período em que ocorreram. Paradoxalmente percebe-se que ao mesmo tempo em que as "autoridades" ditavam através de regras de Decoração as tendências e o certo/errado, impunham questões como a individualidade do caráter que deveria ser refletido nos espaços residenciais. Somente muito tempo depois percebeu-se que o bem estar moral (status/beleza/estética) deveria dar lugar ao pensamento sobre o bem estar físico (função/conforto/ergonomia). Ou seja, voltando às raízes do pensamento lá nas cavernas: como melhor utilizar o espaço disponível.

Não vou estender-me aqui analisando a História recente desta profissão (séculos XIX e XX) já que existe farto material disponível sobre este assunto em livros e na internet. Mesmo que, na maioria das vezes diretamente ligados à prática da Arquitetura, percebe-se que esta práxis não faz parte da mesma afinal, o elemento tratado e os objetivos são distintos em sua essência.

Oficialmente, atribui-se o nascimento de nossa área à passagem do Renascimento para o Barroco. Fica evidente a tentativa de ligação da nossa história à evolução dos estilos arquitetônicos, tanto que Le Brun - um arquiteto do século XVII é considerado o primeiro decorador de interiores da história, conforme nos aponta GIBBS (2009), mais precisamente quando o classicismo do Renascimento italiano começou dar lugar para o estilo Barroco, caracterizado por sua teatralidade e exuberância ornamental. Esse estilo difundiu-se pelo sul da Alemanha, na Áustria, na Espanha e em Portugal. Quando começou a se manifestar na França e na Inglaterra haviam poucos arquitetos que definiam os interiores das edificações que projetavam. Os projetos de maiores proporções eram desenvolvidos pelos artesãos especializados, que os realizavam baseados nas gravuras de arquitetos italianos.

Perceba que há um equívoco - para mim, proposital - no discurso atual da Arquitetura quando alegam que os projetos de interiores SEMPRE fizeram parte da práxis dos arquitetos. Le Brun assumiu exclusivamente a responsabilidade de realizar o projeto de interiores do Palácio de Versalhes pois os arquitetos responsáveis pelas intervenções na edificação, François Mansart e Louis Le Vau, perceberam que não iriam conseguir atender a todos os aspectos do projeto (estruturais, funcionais e estéticos) sozinhos. As exigências do projeto de interiores deveriam ser tão ricas em detalhes - principalmente que representassem o status do cliente, o Rei Henrique VI que um artesão sozinho, por mais especializado que fosse, provavelmente não conseguiria atingir os objetivos criativos, inovadores e estéticos necessários. Mas não

\footnotetext{
${ }^{19}$ Isso rompe com o ideário de que a definição dos espaços internos sempre foi uma prerrogativa da Arquitetura.
} 
se sabe - ao menos oficialmente - se Le Brun realmente desenvolveu sozinho estes projetos ou se o fez em parceria com estes artesãos, dada a complexidade dos detalhamentos e das estruturas do mobiliário e objetos decorativos. E, notadamente, os artesãos dominavam técnicas e materiais específicos que os arquitetos desconheciam.

Digo isso pois neste mesmo período, século XVII, o rei Henrique VI concedeu proteção real aos artesãos (marceneiros, carpinteiros, ferreiros, pintores, costureiras, etc.) reconhecendo a importância destes profissionais que eram, na verdade, aqueles

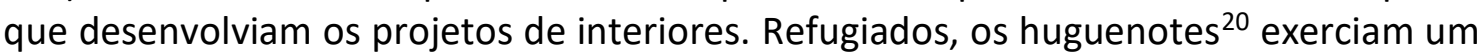
papel importante na evolução do Design de Interiores inglês ume vez que muitos deles eram artesãos altamente qualificados em suas especialidades. (GIBBS, 2009).

Percebe-se claramente então, que o inicio real da área está intrinsecamente ligado ao labor dos artesãos bem como, ao ser humano e a sua prática vernacular. Nesta prática, o projetar - aqui com significado de analisar e pensar em como solucionar um problema - está intimamente ligado ao fazer que é repassada de geração em geração. Isso significa que estes artesãos, muito antes da ideia de projeto de Design introduzida pós Revolução Industrial, já haviam produzido padrões (pensamentos e projetos) que eram seguidos para a produção de objetos e repassados adiante de maneira informal seja pela observação ou pelo aprendizado prático como assistente. Não havia conhecimento teórico acerca do que estava sendo feito, mas sim, um conhecimento empírico do por que, para que e como fazer.

No passado, muitos objetos foram sistematicamente produzidos com projetos muito sofisticados e com a mesma falta de compreensão da base teórica. É comum chamar esse procedimento de "projeto de ferreiro", porque o artesão, tradicionalmente, projetava os objetos enquanto os fazia, sem desenhos técnicos, baseado em padrões antigos passados de geração em geração. (LAWSON, 2011, pp. 30).

Os esquimós são um exemplo perfeito desta prática vernacular ${ }^{21}$, pois nunca precisaram de um profissional habilitado em projeto para criar e aperfeiçoar o modelo construtivo. Eles vão recriando e adaptando-o conforme suas necessidades mudam. "Segundo Kingston Wm. Heath (2003), o vernacular é produzido por um indivíduo para seu próprio uso, ou por construtores anônimos e locais que respondem a fórmulas localmente adaptadas"22. Nesse sentido, incluem-se aqui também as tribos indígenas que, com suas ocas e aldeias, definiam o melhor uso para cada espaço interno ou externo sem haver um projetista para isso.

\footnotetext{
${ }^{20}$ Recebia o nome de huguenote todo o seguidor da religião protestante na França. Eram na maioria calvinistas (acreditavam nos ensinamentos de João Calvino) e membros da Igreja Reformada. A origem do termo vem dos católicos franceses, que o criaram baseando-se no nome de Besançon Hugues, líder religioso suíço. (http://www.infoescola.com/religiao/huguenotes/).

${ }^{21}$ Em 1997, foi lançada "The Enciclopedia of Vernacular Arquitecture", o primeiro estudo internacional sobre edifícios vernáculos, editada por Paul Oliver. Já que fala-se tanto sobre "Arquitetura Vernacular" destacando a sua relevância e importância histórica para a área, podemos também utilizar este termo para contestar e rever a nossa História: o Design Vernacular.

22 Ibarra. O Design e a Valorização do Vernacular ou de Práticas Realizadas por Não-Designers. Blucher, 2014.
} 
É fato que quando a sociedade é submetida a mudanças rápidas - como é o caso da Revolução Industrial - e a necessidade de artefatos ${ }^{23}$ aumenta, seja em variedade ou em quantidade. Assim, é óbvio que a produção artesanal torna-se incapaz de suprir à demanda e faz-se, então, necessária uma abordagem mais ampla e técnica: o processo profissionalizado de concepção de produtos que atendam às novas necessidades aliado à rápida manufatura. Percebe-se então que o projeto, como o conhecemos hoje, é fruto de uma reação às necessidades impostas pelas mudanças sociais e culturais da sociedade e ainda, dentro de contextos bem específicos.

Mas, voltando à História de nossa área, observando os elementos vernaculares e os subjetivos existentes ${ }^{24}$, podemos concluir que a forma de "pensar o melhor uso" dos diversos espaços utilizados pelos seres humanos (base de nossa profissão) de maneira confortável, segura e eficiente ao mesmo tempo em que satisfaz as necessidades estéticas vem de longe, de eras bem mais distantes.

Na verdade, este pensar sobre as formas de usar os ambientes pode ser notado já, arrisco-me a afirmar, antes mesmo da Arquitetura (construção) surgir. Mas disso trataremos um pouco mais adiante ainda neste artigo. Retrocedamos no tempo, nos aproveitando das práticas vernaculares e de pistas espalhadas pela História da humanidade, para que possamos entender este processo.

Antes de Le Brun, nos séculos XV e XVI, durante o período do Renascimento, já encontramos uma renovação sobre a função de criar os espaços interiores ou adequálos ao melhor uso. Neste período, percebemos que existiam, além dos artesãos, alguns arquitetos que tinham abandonado a Arquitetura pura ${ }^{25}$ e enveredado para esta área bastante especifica passando a trabalhar apenas com isso. No entanto, é leviano afirmar que a Decoração ou o Design de Interiores e Ambientes nasceram da Arquitetura por causa disso. Percebam que houve uma necessidade específica (demanda) sobre um objetivo (problema) que não era uma "peça chave" considerada dentro da Arquitetura.

Já no século XII, as casas e templos recebiam cores, mobiliários, panejamentos e objetos decorativos bem como, a entrada de uma "luz" natural através dos rasgos na alvenaria oriundos do movimento Gótico que, após um longo período de escuridão em diversos aspectos que o antecedeu: a Idade das Trevas. Este foi um período onde o processo criativo foi perseguido, ficou estagnado e quase foi eliminado. As Artes e a Arquitetura, bem como as práticas artesanais passaram a seguir padrões que refletiam o período: as guerras medievais (social) e a ascensão da igreja (moral) que geraram um momento de austeridade impostas por estas duas situações.

Retrocedendo ainda mais para o período das grandes civilizações, na Roma Antiga, os ambientes eram ricamente elaborados (estética) e inovaram em um ponto fundamental de nossa profissão: a busca pelo conforto. Os espaços passaram não apenas a servir como um lugar para ser admirado, mas deviam fundamentalmente propiciar o bem estar (conforto e segurança) de seus usuários permanentes e convidados. Esta preocupação com a estética (para mostrar poder e status social)

\footnotetext{
23 "Forma individual de cultura material ou produto deliberado da mão-de-obra humana" HOUAISS. 2001.

${ }^{24}$ As descobertas arqueológicas ignoradas e/ou esquecidas provam isso.

${ }^{25}$ Projetos arquitetônicos, edificações.
} 
levou à renovação na forma de produção dos móveis, com atenção especial à ornamentação, pois agora estes faziam parte do embelezamento dos espaços.

Antes disso, na Grécia Antiga, já conseguimos perceber uma preocupação com alguns cuidados relacionados ao pensar do designer. O mobiliário rústico e feito ao acaso passou a ocupar grande parte da preocupação de seus produtores e a sua construção passou a ser feita com mais cuidado e atenção. Alguns móveis requintados já traziam detalhes em materiais nobres, tais como o marfim e a prata.

Chegamos então a um credito "não oficial" do nascimento do Design de Interiores: o Egito. Neste período já se percebem traços do cuidado dos usuários com relação aos espaços por eles utilizados (vernacular), especialmente dentro de suas casas onde, entre outras coisas, buscavam desenvolver mobiliários utilitários (função) ao mesmo tempo em que, à sua maneira, tentavam torná-los mais agradáveis visualmente e confortáveis com o revestimento de peles e tecidos. Também se percebe nestes mesmos ambientes a existência de murais, acessórios utilitários e objetos decorativos. Tais cuidados refletem claramente a constante preocupação com a organização e o uso dos espaços internos.

Regredindo um tanto mais na linha do tempo chegamos aos homens que utilizavam as cavernas ${ }^{26}$, a primeira "habitação" do ser humano. Cavernas não devem ser tratadas como habitação e sim como abrigos. Vale analisar o que o Dicionário Michaelis descreve os verbetes habitação ${ }^{27}$ e abrigo ${ }^{28}$ bem como buscar a etimologia destes.

Percebe-se claramente com estas definições que, por mais que se faça presente no significado de abrigo o elemento relativo à construção dos abrigos à prova de projéteis e bombas, as cavernas não podem ser consideradas habitações, pois não possuem elementos construtivos projetados. Pelo contrário, são espaços naturais existentes formados pela própria natureza. Os homens primitivos apoderavam-se destes espaços naturais para enfrentar as adversas condições impostas pela natureza. Estes eram os locais perfeitos para aquecê-los em noites frias, para protegê-los da chuva, do vento e dos animais. Era bastante comum também que eles colocassem na entrada destas cavernas grandes pedras ou fizessem fogueiras para evitar a entrada de animais garantindo assim a segurança de todos os usuários.

Dentro das cavernas percebemos outros elementos que também podemos considerar como o início da forma de "pensar o melhor uso para os espaços" utilizados por eles já que a caverna era dividida em áreas distintas e basicamente bem definidas, dependendo da dimensão do ambiente. Havia a área para dormir, a área de convivência e a área para preparo e consumo de alimentos. Também encontram-se provas de que haviam preocupações com o conforto, mesmo que de forma rudimentar, ao observarmos as "camas" feitas de capim. As imagens retratadas nas

\footnotetext{
${ }^{26}$ ca.ver.na - sf (lat caverna) 1 Cavidade de grandes dimensões em monte, rochedo ou sob a terra; antro, furna, gruta. (MICHAELIS).

27 “ha.bi.ta.ção - sf (lat habitatione) 1 Ato ou efeito de habitar. 2 Lugar em que se habita. 3 Casa, moradia, residência, vivenda. 4 Habitat. 5 Designação do lugar ou sítio onde os animais se recolhem." (MICHAELIS - Grifos do autor).

28 "a.bri.go - sm (lat apricu) 1 Tudo que serve para abrigar das intempéries: (...) os animais se juntavam debaixo das árvores". 2 Cobertura, galpão, telheiro. 3 Algo que oferece proteção ou refúgio contra exposição, dano físico, ataque, observação, perigo etc. (...)." (MICHAELIS - Grifos do autor).
} 
paredes, as pinturas rupestres ${ }^{29}$, retratavam aos usuários a sua história, as formas de agir e de planejamento do clã em suas ações bem como, de certa forma, mostravam o status do clã. Podem ser consideradas também como elementos decorativos ligados diretamente à estética. E todos estes elementos fazem parte do pensar o uso do espaço disponível, assim como o Design de Interiores faz hoje.

\section{CONCLUSÃO}

Como se vê, a preocupação com o bem estar, numa visão holística, dentro e fora dos espaços utilizados pelo ser humano está presente há muito tempo na História da humanidade. Devemos levar em consideração que o homem ocupou espaços para seu conforto e, independente de classe social, cada qual procurava o melhor modo para viver.

Com este breve estudo histórico, ao observarmos a trajetória da humanidade, é fácil notar que a forma como utilizamos os diversos espaços em nosso dia a dia, assim como a constante preocupação com o bem estar, o conforto, a segurança e a estética estão enraizados desde os nossos primórdios. Isso reflete claramente o processo de trabalho de um designer: analisar o espaço a ser ocupado, encontrar o problema - seja de qual natureza for - e buscar a melhor solução para ele. E esta é a forma de pensar do designer. Há muito da forma de pensar do designer sendo empregado desde os primórdios para ser descartado ou desconsiderado.

Longe de fechar o assunto e sim, visando abrir caminho apontando questionamentos que merecem ser mais aprofundados através de pesquisas mais direcionadas e específicas sobre a atuação profissional em cada período da existência humana, devemos reavaliar toda a base histórica do Design, reconhecendo nos antigos mestres-artesões o início da profissão Design. Os lastros históricos estão espalhados em diversos documentos históricos como já exposto neste artigo. Basta encontrá-los, reinterpretá-los de acordo com as características e bases de cada segmento do Design e reescrever a nossa História, a nossa Real História.

\section{REFERÊNCIAS}

DE CERTEAU, Michel. Escrita da história. Rio de Janeiro, Forense Universitária. 1982.

DE WOLF, Elsie. The house in good taste. New York, The Century Co. 1913.

DIVERSOS. The Lady's Pictorial - In print: 1891. Disponível em <http://www.cardiff.ac.uk/>. Acesso em 05 de fevereiro de 2016.

FORTY, Adrian. Objetos de Desejo. Edição revisada e ampliada. Ed. Cosac Naify, 2013. A VERSÃO original data de 1986.

GROPIUS, Walter. Bauhaus: Novarquitetura. 2 ed. São Paulo, Perspectiva. 2004.

HOUAISS, A. Dicionário Houaiss da Língua Portuguesa. Rio de Janeiro, Ed. Objetiva. 2001.

\footnotetext{
${ }^{29}$ ru.pes.tre - adj $m+f$ (lat rupes) 1 Relativo às rochas. 2 Que vive nas pedras. 3 Bot Diz-se do vegetal que cresce sobre os rochedos. 4 Inscrito ou desenhado nas rochas: Pinturas rupestres. (MICHAELIS).
} 
IBARRA, Maria Cristina. et. al. In: $\mathbf{1 1}^{\circ}$ Congresso Brasileiro de Pesquisa e Desenvolvimento em Design. Gramado, Blucher. 2014.

LAWSON, Bryan. Como arquitetos e designers pensam. São Paulo, Oficina de Textos, 2011.

NETO, Mariano Lopes de Andrade; et. al. Bauhaus e o Jardim de Epicuro: Discurso e Prática. São Paulo, Estação das Letras e Cores. 2011.

WOLF, Tom. Da Bauhaus ao nosso caos. Rio de Janeiro, Ed. Rocco. 1990. 